\title{
Carlos Ruiz. Desde la teoría clásica una ciencia social crítica e interdisciplinar ${ }^{1}$
}

\author{
Claudio Díaz Herrera*
}

Carlos Ruiz Encina, director de la Escuela de Sociología de la Universidad de Chile, Sociólogo, Magíster y Dr. en Estudios Latinoamericanos de la misma casa de estudios; investigador y académico de pre y posgrado. Especialista en Sociología Latinoamericana, modelos de desarrollo y transformaciones del Estado en América Latina, estructura social y su relación con la modernización, así como procesos de formación de actores sociales y conflictividad social. Dentro de sus principales libros encontramos Obras Completas de Enzo Faletto (2009); Conflicto social en el neoliberalismo avanzado. Análisis de clase de la revuelta estudiantil en Chile (2013); Los chilenos bajo el neoliberalismo. Clases y conflicto social (2014) y; De nuevo la sociedad (2015).

La siguiente entrevista es un fragmento de una conversación más extensa, donde Ruiz comenta lo que entiende por ciencias sociales, su devenir y cuál debiera ser el rol de esta área de estudios. En este sentido, podemos encontrar una convergencia entre elementos propuestos por Eduardo Devés y Manuel A. Garretón, en relación a la necesidad de fortalecer una ciencia social crítica, dialógica con otras disciplinas de las ciencias humanas y sociales, que logre tomar distancia de particularidades y que permita determinar qué tipo de sociedad estamos y queremos vivir mediante la generación de una teoría de largo alcance, donde Ruiz propone la necesidad de volcar la mirada constantemente a los clásicos de la teoría social y sacar a las ciencias sociales de una labor administrativa.

\footnotetext{
${ }^{1}$ Entrevista realizada en la Facultad de Ciencias Sociales de la Universidad de Chile, el 21 de abril de 2015 a través del financiamiento del Fondo de Iniciación en Investigación Social No 16783/2015 de la FACSO-UCH.

* Doctorando en Ciencias Humanas, Facultad de Psicología - Instituto de Estudios Humanísticos, Universidad de Talca. Talca, Chile. Correo electrónico: cldiaz@utalca.cl
} 
¿Qué ha significado para Ud. estudiar las ciencias sociales? -Creo que soy un poco visto desde afuera por los colegas, me he dedicado a reponer un diálogo con los pensamientos clásicos y traerlos a colación, he sido un tanto opuesto a todo este giro medio posmoderno de los últimos tiempos que en los años $90-y$ de una manera muy conservadora y contraria de los que parecían ultra moderno-, era una especie de trampa a la modernidad como diría Habermas, y no aportaba mucho de novedad, sino que naturalizaba muchas veces una transformación estatal que se heredó del régimen autoritario. Entonces en función de eso, recuperar y no solamente trasladar los pensamientos clásico, y ponerlos arriba de una situación que ha cambiado, eso implica un diálogo crítico de apropiación con esos autores clásicos.

Weber, Marx, Durkheim ¿Qué nos pueden hablar ellos para plantearlos sobre el presente y no de la forma cómo fueron usados en los 60? Ellos no se agotaron ahí, después sobre la crisis de eso se monta la discusión de los 90, del posmodernismo en Chile a fines de los 80 en la transición para adelante, estoy hablando de la escena chilena, que es distinto si lo vemos en Europa, y ante eso, reponer el análisis de clases, o el análisis del carácter social del Estado y que no es una cuestión solamente marxista, es weberiana que está en las bases en los fundamentos de la sociología.

En el último tiempo se construyó un esquema que naturalizaba y abocaba a la administración de políticas públicas muy focalizadas, una abstracción de todo este tipo de temas sobre los cuales yo por lo menos he trabajado o trabajo sobre América Latina, el recuperar la noción de modelos de desarrollo, de Estado, de alianzas de clase que se enquistan en los Estados, etc., una discusión de Cardoso y Faletto, de Dependencia y Desarrollo, uno de los clásicos de la Sociología más grande que hay en América Latina. Traer toda esa discusión al análisis de la acción social actual, etc., pero no como si fuera calco o copia, sino que una reactualización de eso. Eso te plantea dilemas teóricos, que yo creo las CC.SS. más posmodernas quiso eludirlo, como un salto hacia adelante, al vacío, más evasivo. Yo me apartaría un poco de los relatos que en función de esa línea, construyeran como el fin de la Sociología, el fin de metarrelatos y una apuesta a los microrrelatos, al fin de la certidumbre, como el fin de la historia, es decir, aquí se separó todo como Fukuyama, entonces “ibueno ya listo!, no hay más futuros que imaginar”, eso es hacerle un mal favor a la noción de libertad kantiana, como la humanidad con capacidad de libertad de proponerse, soñar y construir su propio mundo que es la idea de Kant, entonces era conservador por donde lo mires, no solamente antimarxista, era anti todo el pensamiento de la ilustración, entonces era fuerte, terrible y creo que eso se está desmoronando.

Entonces aparece una oportunidad de empezar de nuevo a replantearse el vínculo entre las distintas disciplinas que permitan reconstruir una noción de 
CC.SS., porque de alguna manera en ese rato, fue deshilachada, y además decretada casi "out", bueno Brunner decreta el fin de la sociología, o sea ¿Qué cosa más oscura para la mente humana, qué más oscuridad? ¡Esa cuestión es inquisición prácticamente!, mira en lo que caímos, decretar el fin de las CC.SS. y al amparo de eso, la formación de las burocracias que en ese tiempo eran profesionales que se iban formando frente a los discursos de naturalización del gasto social focalizado, equilibrios macroeconómicos, etc., como un tipo de aparataje administrativo. Entonces si tú te fijas, es un vaciamiento intelectual en el fondo, porque "el grueso de la intelectualidad sucumbe a la corte" por decirlo de alguna manera, la producción de intelectualidad cortesana en muy fuerte en la transición, y por lo tanto, lo que se pierde es la capacidad de pensamiento crítico, lo que advirtió en el momento de la transición Lechner, Faletto, más adelante Moulian, y hoy lo está reclamando Garretón, pero es un momento en que esto se perdió, entramos en un túnel, en una situación oscura para las CC.SS. y nos aislamos incluso de la discusión social francesa. ¡Aparecíamos en la punta de la globalización!, cuando era una globalización mercantil, comercial, ahí éramos unos fenicios, pero no intelectual, ni cultural, además no teníamos ninguna relación con América Latina en la década de los 90, acuérdate que nos apartamos de todos, estábamos mirando a los dragones, Singapur, los tigres.

Hoy aparecen a raíz de esto lo que estamos llamando malestar, este rugir de la sociedad de nuevo ¿Cómo entenderla? Esto implica un diálogo en el cual hay nuevas desigualdades, nuevos procesos de diferenciación social, nuevos grupos sociales que pueden decantar incluso en nuevas clases, con nuevas fisonomías, pero también a eso están asociadas nuevas patologías sociales, entonces ahí hay una psicología con la cual se puede dialogar y que la psicología solo no lo resuelve sin nosotros, y nosotros solos sin la psicología, con la antropología, o sea, hay mucho que empezar a reconstruir en el fondo como un paradigma en CC.SS. en este rato, y en función de los que tenemos ahí afuera en la calle, no solamente los malestares que están marchando y que generalmente son los más jóvenes o movimientos más activos, sino que sabemos que hay otro tipo de malestar en un proceso de individuación extrema, ¡ya lo advirtió el PNUD y Lechner! eran las paradojas de la modernización, "estamos creciendo como nunca, pero la gente se siente mal y está muerta de miedo" ¿qué pasa entonces?

¿Qué son para Ud. las ciencias sociales? - La posibilidad de ese diálogo entre diferentes disciplinas del conocimiento, lo otro es sumar compartimentos estancos disciplinares, en el fondo, la sociedad es una sola y por lo tanto, construir como se dice una "ciencia de la sociedad" implica el diálogo, la promiscuidad si tú quieres disciplinar, cuando estos cortes disciplinarios han sido arbitrariamente establecidos en cierto modo, como una forma de elaborar quantum de conocimiento 
y quantum de metodología, etc. Pero de hecho el mismo tema de las metodologías ya es cada vez más promiscua, en las mismas metodologías están siendo manejadas de una manera muy transversal para distintas disciplinas que comprenden las CC.SS., y yo diría que el paradigma es exactamente contrario a decretar su muerte, al contrario, como hoy estamos ante una sociedad que se nos presenta con muchos rasgos nuevos, la posibilidad de abordarla, es realmente una demanda de ese diálogo que podríamos decir interdisciplinar. En el fondo, cuando uno está diciendo interdisciplinar está diciendo CC.SS., pero esto implica también sacar entonces al psicólogo de su encierro y ahí entender que su perspectiva clínica puede dialogar con situaciones que están ocurriendo en la sociedad, es decir, las crisis del individuo, el páramo del individuo como dicen los franceses, o una individuación extrema. Esto tiene muchos nombres, el ciudadano "credit card" dice Moulian, empieza a crear un tipo de conflicto en el fondo en términos de los patrones de modernización y la forma en que afectan al individuo lo que te obliga a un diálogo complejo a nivel de CC.SS., y no de compartimento estanco disciplinar.

¿Hacia dónde tienen que ir las ciencias sociales? -Apropiarse del cambio de la sociedad chilena, volver a vincular las CC.SS. y la sociedad, y sacarla de la administración, el problema es que donde no hay imaginación hay administración. 